\title{
LA CUSTODIA PROCESIONAL DE LA HERMANDAD SACRAMENTAL DEL SALVADOR DE SEVILLA
}

\author{
POR JOSÉ RODA PEÑA
}

\section{A. ESTUDIO DOCUMENTAL.}

La autoría de la custodia procesional de la Hermandad Sacramental establecida desde 1543 en la antigua Colegiata hispalense del Salvador, quedó desvelada en 1930, gracias a las noticias publicadas por Heliodoro Sancho Corbacho ' . Se trata del platero de mazonería Miguel Sánchez, vecino de la collación de Santa María, quien en 1598 ocupaba el cargo de veedor de los plateros sevillanos, con nombramiento de marcador por el Cabildo secular hispalense. En 1597 había sido Prioste de la Hermandad de San Eligio, y en 1609 fue llamado por el Cabildo metropolitano para que diese su parecer sobre la custodia de oro que habían ejecutado Lázaro Hernández Rincón y Valderrama ${ }^{2}$.

La documentación aportada por el citado investigador, así como por María Jesús Sanz en $1976^{3}$, junto a la que nosotros hemos hallado en el archivo de la corporación

1. SANCHO CORBACHO, Heliodoro: Contribución documental al estudio del Arte sevillano en "Documentos para la Historia del Arte en Andalucía". T. II. Sevilla, 1930, pp. 253-254; esta misma documentación vuelve a ser publicada como inédita por PERALES PIQUERES, Rosa María: "Nuevos datos sobre la custodia procesional de la Hermandad Sacramental del Salvador" en Homenaje al Profesor Hernández Díaz. Sevilla, 1982, pp. 527-529. Además, transcribió mal el año de la carta de pago fechada el 5 de noviembre de 1612, transformándolo en 1621, con lo cual ofrece a lo largo de su artículo toda una serie de conclusiones erróneas acerca del proceso constructivo.

2. CRUZ VALDOVINOS, José Manuel: Catálogo de la Exposición Cinco siglos de platería sevillana. Sevilla, 1992, p. LXXXI. Dicho puesto también lo ejercía en 1613; GESTOSO Y PEREZ, José: Ensayo para un diccionario de los artífices que florecieron en Sevilla desde el siglo XIII al XVIII, inclusive. T. II. Sevilla, 1900, p. 320.

3. SANZ SERRANO, María Jesús: La Orfebrería Sevillana del Barroco. Sevilla, 1976. T. I, pp. 188-190 y T. II, pp. 307-309; IDEM: "Otras procesiones del Corpus Christi en Sevilla" en Isidorianum, n³. Sevilla, 1993, pp. 167-169. 
eucarística, aclara el dilatado y complejo proceso constructivo de esta custodia de asiento (Lám. 1). La primera carta de pago la firma Miguel Sánchez el 5 de noviembre de 1612, y asciende a un total de 16.953 reales $^{4}$. La segunda, fechada el día 31 del mismo mes y año, aclara que las cantidades que se le iban entregando por parte del Alcalde Diego de Soto "son de la limosna que los hermanos de la dicha Cofradía an demandado de noche en la dicha collación de San Salvador" 5.

El 4 de febrero de 1620, Miguel Sánchez acordó con la Hermandad modificar las condiciones del primitivo contrato. En efecto, los tres cuerpos con que debía contar la custodia, quedaron reducidos a dos con su correspondiente remate. Desde entonces, hasta la conclusión de la obra, estipulada para la festividad del Corpus Christi del año 1621, la cofradía habría de entregarle 400 ducados de vellón ${ }^{6}$. Este plazo de terminación parece que se cumplió, según refleja la inscripción que se desarrolla en cuatro cartelas situadas en el pedestal de su primer cuerpo: "ESTA CUSTODIA MANDARON HACER LOS HERMANOS DE LA COFRADIA DEL SMO. SA/CRAMENTO DE LA IGLESIA DEL S. SAN SALBADOR I ES SUIA PROPRIA DE LA DI/CHA COFRADIA HECHA A SU COSTA I DE LOS HERMANOS DE ELLA AÑO 1621 SIENDO/ ALCALDES DIEGO DE SOTO I DIEGO DE LEON MAIORDOMO JUSEPE MARTINEZ" ?

Del estudio de las quince cartas de pago que hemos podido localizar ${ }^{8}$, se infiere que los cobros se congelaron en 1615 y entre marzo de 1616 y febrero de 1620 , períodos en los que quizás los trabajos también quedaron paralizados. A estas escrituras públicas, habrían de sumarse otros recibos por cantidades inferiores, igualmente signados por Miguel Sánchez a partir de 1620. Dos comprobantes de 50 reales cada uno se fechan, respectivamente, el 14 de junio y el 9 de septiembre de 1620; otro de 128 reales se firma el 27 de noviembre de ese mismo año, donde consta que los mismos se pagaron a "Gaspar de Vozmediano, platero de la bóveda de la custodia que me labró" 9; el 2 de julio de 1621, Sánchez recibió a cuenta otros 126 reales, donados a la Hermandad por el platero Juan de la Peña; finalmente, quedan anotados, aun sin fechar, 24 reales,

4. SANCHO CORBACHO, Heliodoro: Contribución documental al estudio del Arte sevillano. Op. cit., pp. 253-254; (A)rchivo de la (Hermandad) (S)acramental de (P)asión de (S)evilla. Sección Sacramental. Leg. 77. Capilla Sacramental y Custodia. "Títulos de la custodia de plata que tiene la Cofradía del Santíssimo Sacramento de la Yglesia Collegial de Nro. Sr. S. Salvador de esta Ciudad. Visto este año de 1685", s.f.

5. Ibidem.

6. SANCHO CORBACHO, Heliodoro: Contribución documental al estudio del Arte sevillano. Op. cit., p. 254.

7. Catálogo de la Exposición de Valdés Leal y de Arte restrospectivo. Sevilla, 1923, p. 74.

8. A.H.S.P.S. Sección Sacramental. Leg. 77. Capilla Sacramental y Custodia. "Títulos...". Op. cit., s.f.; la única carta de pago que no figura en tal documento es la fechada el 12 de febrero de 1620 , que cita Sancho Corbacho en su Contribución documental al estudio del Arte sevillano. Op. cit., p. 254.

9. VALDOVINOS, José Manuel: Catálogo de la Exposición Cinco siglos de platería sevillana. Op. cit., pp. 70 y 101. Fue nombrado platero catedralicio en 1620; tres años más tarde, blanqueó y agregó un banco nuevo al segundo cuerpo de la custodia de Juan de Arfe. 
entregados "al que escrivió las tarxas" ${ }^{10}$. Por tanto, entre 1612 y 1621 , la Hermandad entregó a Miguel Sánchez un total de 34.107 reales.

Una de las cláusulas de la escritura de concierto establecía que, concluida la obra de la custodia, ambas partes -platero y Hermandad- nombrarían tasadores, con el fụn de que se entregaran al orfebre cien reales por cada marco de su hechura. Dichos tasadores elogiaron la espléndida pieza recién finalizada, decidiendo que la corporación había de pagar 11.848 reales a Miguel Sánchez. Como la Hermandad no podía hacer frente a tan cuantioso dispendio, el platero interpuso pleito contra los bienes de aquélla. Tras una serie de deliberaciones, la cantidad se vio reducida a 8.900 reales, de los cuales 2.110 se obtuvieron de limosnas de los cofrades, mientras que los 6.790 restantes los prestó la benefactora $D^{a}$ María de Comas. Este préstamo le fue devuelto entre el 28 de octubre de 1626 y el 5 de febrero de 1631 , fecha en la que la custodia procesional quedó completamente sufragada. Su coste total ascendió a 43.007 reales ${ }^{11}$.

A partir de entonces se han sucedido una serie de reformas y restauraciones, que fueron alterando la primigenia fisonomía manierista de esta pieza príncipe de la orfebrería sevillana del primer cuarto del siglo XVII.

En 1633 consta un descargo de 85,5 reales por la plata y hechura del remate que se le hizo a la custodia. Se trata de la cruz que coronaba el pequeño templete superior, en cuyo interior se aloja una campanilla ${ }^{12}$. Esta novedad aparece reflejada por primera vez en el inventario de 1646, cuando se anota "una custodia con treynta y dos colunas de plata y diez y seis remates mayores y menores de plata con cruz al remate" ${ }^{13}$. Posteriormente, según veremos, dicha cruz fue sustituida por la escultura de la Fe.

En 1652, el platero Pedro de Valenzuela ejecuta el arca eucarística, que se colocaba en el interior del primer cuerpo de la custodia, en el Monumento del Jueves Santo. La suma de 1.300 reales se le abonó en tres plazos ${ }^{14}$. Este arca, que reemplazó a una primitiva urna de madera, fue sustituida a su vez por un "sepulcro" labrado en 1668 por Juan Birto del Pinar ${ }^{15}$, descrito en el inventario de 1678 como "un sepulcro de plata sincelado que tiene ensima tres cruzes con sus montesitos, todo de plata"16. Esta pieza no ha llegado hasta nosotros.

10. A.H.S.P.S. Sección Sacramental. Leg. 77. Capilla Sacramental y Custodia. "Títulos...". Op. cit., s.f.

11. Ibidem.

12. A.H.S.P.S. Sección Sacramental. Leg. 28. Libro $1^{\circ}$ de Cuentas 1627-1691. Data de 1633, f. 37r.

13. A.H.S.P.S. Sección Sacramental. Leg. 2. Libro $1^{\circ}$ de Acuerdos 1630-1644. Inventario 21 -enero-1646, f. 70v.

14. A.H.S.P.S. Sección Sacramental. Leg. 46. Mayordomía 1650-1700. Cuentas de 1652.

15. Ibidem. Cuentas de 1668. El 26 de octubre de 1668 Juan Birto del Pinar declara haber recibido del Mayordomo de la Sacramental "nobenta y dos marcos menos media onza de plata para la obra que e de aser del banco de la custodia y el sepulcro y Ebangelistas y otras cosas, y está consertado la urnia y sepulcro a tres pesos de hechura cada marco".

16. A.H.S.P.S. Sección Sacramental. Leg. 1. Inventarios. "Libro de imbentarios de la Cofradía del SSmo. Sacramento de la Yglesia Colegial. Año de 1678". Inventario 5-enero-1678, f. 2r. 
Ese mismo año de 1668, el propio Juan Birto se encargó de realizar un pedestal para la custodia, por cuya labor percibió 4.973 reales $^{17}$. Dicho pie fue desbaratado en 1684 , a fin de ejecutar con su plata una media luna para la imagen concepcionista de Nuestra Señora del Voto, cotitular de la Sacramental del Salvador ${ }^{18}$.

Entre 1670 y 1672 se enriqueció la iconografía de la custodia con la adición de ocho angelitos fundidos en plata; sabemos que por cuatro de ellos se pagaron 1.185 reales y tres cuartillos de vellón, sin que figure en la documentación el nombre del artífice ${ }^{19}$. Estos ángeles fueron retirados de su primitivo emplazamiento por el orfebre Cayetano González, quien en 1943 los incorporó a los faroles angulares y capillas frontal y trasera de las argénteas andas procesionales de Nuestro Padre Jesús de la Pasión. En 1992, con motivo de la última restauración de la custodia por Orfebrería Villarreal, se han recuperado cuatro originales, siendo colocados en la cornisa del segundo cuerpo de la custodia, existiendo el proyecto de reintegrar en el conjunto los restantes, sustituyéndolos en el paso por copias en plata de ley ${ }^{20}$.

La primera mención que hemos hallado sobre la escultura en madera policromada del Cristo atado a la columna, que se ubica en el interior del segundo cuerpo de la custodia, data de 1676, cuando se abonan 55 reales por "aderezar la hechura del Sto. Xpto. amarrado a la columna que se pone en el monumento, de encarnarlo y doralle la peana" ${ }^{21}$. Esta imagen (mide $48 \mathrm{cms}$. de alto con la peana y $37 \mathrm{cms}$. sin ella) puede fecharse en el tercer cuarto del siglo XVII, siendo obra anónima sevillana (Lám. 2). La efigie se muestra erguida, formando sus manos y muñecas un solo bloque con el fuste de la columna toscana que se levanta a su izquierda. El peso del cuerpo recae sobre la pierna derecha, al par que la izquierda queda exonerada. Fue restaurado en 1991 por el Taller Isbilia, recuperando así el estofado original del sudario y de la columna; dicha labor importó 84.000 pesetas. En origen, su cabeza ostentó potencias de plata, hoy perdidas 22 .

El inventario de bienes de 1678 nos aclara que la custodia contaba asimismo con "quatro pirámides de plata... como de una sesma de alto", las cuales fueron deshechas en 1687 para "hazer el visso" ${ }^{23}$.

Quizás por influencia del Cabildo catedralicio, que había ordenado sustituir en 1668 el primitivo grupo de la Fe de la custodia de Juan de Arfe por una imagen de

17. A.H.S.P.S. Sección Sacramental. Leg. 3. Libro $2^{\circ}$ de Acuerdos 1644-1694. Cabildo Ordinario 21-octubre-1668, f. 75v; Leg. 28. Libro $1^{\circ}$ de Cuentas 1627-1691. Cuentas de 1668, fs. 207v-208r.

18. A.H.S.P.S. Sección Sacramental. Leg. 3. Libro $2^{\circ}$ de Acuerdos 1644-1694. Cabildo Ordinario 26-febrero-1684, f. 170r.

19. A.H.S.P.S. Sección Sacramental. Leg. 28. Libro $1^{\circ}$ de Cuentas 1627-1691. Cuentas de 1670-1672, f. $213 \mathrm{r}$.

20. RODA PEÑA, José: "Paso de Nuestro Padre Jesús de la Pasión" en Catálogo de la Exposición $L a$ Pasión. Sevilla, 1992, s.p.

21. A.H.S.P.S. Sección Sacramental. Leg. 28. Libro $1^{\circ}$ de Cuentas 1627-1691. Cuentas de 1676, f. 239v.

22. A.H.S.P.S. Sección Sacramental. Leg. 1. Inventarios. "Libro de imbentarios...". Inventario 5-enero-1678, f. 2 r.

23. Ibidem; Ibid. Inventario de 1687, f. 14. 
la Inmaculada, obra de Juan de Segura, la Hermandad Sacramental del-Salvador acordó en 1684 incluir también en el primer cuerpo de su custodia una efigie concepcionista de plata. Consta que llegó a ejecutarse un modelo en terracota, pero nunca llegó a plasmarse en el rico metal ${ }^{24}$.

En 1687, parece que se reformaron los arcos de medio punto del primer cuerpo de la custodia. La plata costó 4.440 reales, mientras que la mano de obra del carpintero ascendió a 112 reales, y la del platero a 1.320 reales $^{25}$. Todo ello se relaciona adecuadamente con la decoración vegetal de carácter carnoso y turgente que muestran las enjutas exteriores de los aludidos arcos, propia del pleno momento barroco.

Pocos años después, en 1691, se decide enriquecer con perlas el viril de la custodia, así como sustituir el remate de la cruz por una escultura fundida en plata de la Fe, que desde entonces asienta sobre el templete que cobija la campanilla ${ }^{26}$. $\mathrm{Al}$ año siguiente, se estrenará una parihuela para esta custodia, utilizada en las procesiones de Corpus por las calles de la collación, que contaba con un rótulo que decía: "SOY DE LA ARCHICOFRADIA DEL SANTISIMO SACRAMENTO, ZITA EN LA YGLESIA COLLEXIAL DE NUESTRO SEÑOR SAN SALVADOR. AÑO DE MILL SEISCIENTOS Y NOVENTA Y DOS" ${ }^{27}$.

En 1693 culminarán las reformas acometidas durante el siglo XVII en la custodia procesional, con una serie de actuaciones que, al igual que las que acabamos de reseñar, estuvieron encaminadas a barroquizar su primitiva estructura, imbuida de un poderoso aliento clasicista.

Entre enero y mayo de 1693 el maestro platero Diego Gallegos realizó ocho jarritas de plata para la custodia, cada una de las cuales pesó 12 onzas. Al término de su ejecución, recibió la suma de 2.151 reales $^{28}$. Al respecto, conviene señalar que Diego Gallegos ingresó como cofrade de la Sacramental del Salvador el 30 de marzo de 1684 , en unión de su esposa Inés Suárez de la Rosa ${ }^{29}$. Tenemos documentados hasta 1725 diversos trabajos suyos de escasa consideración, acometidos por encargo de la Hermandad, junto a otros de mayor envergadura, como la labra en 1704 de la desaparecida peana de Nuestra Señora del Voto, por la que cobró 7.035 reales. El año de su óbito, que hasta ahora era desconocido, lo podemos fijar en $1734^{30}$.

24. A.H.S.P.S. Sección Sacramental. Leg. 3. Libro $2^{\circ}$ de Acuerdos 1644-1694. Cabildo Ordinario 26-febrero-1684, f. 170r.

25. A.H.S.P.S. Sección Sacramental. Leg. 28. Libro $1^{\circ}$ de Cuentas 1627-1691. Cuentas de 1687, f. $326 \mathrm{r}$.

26. A.H.S.P.S. Sección Sacramental. Leg. 3. Libro $2^{\circ}$ de Acuerdos 1644-1694. Cabildo Ordinario 4-enero-1691, f. 284v; Leg. 1. Inventarios. "Libro de imbentarios...". Inventario 1-enero-1697, f. $21 \mathrm{v}$. "...y es declarazión que la Cruz que tenía la custodia se desbarató para hazer la fee".

27. (A)rchivo (G)eneral del (A)rzobispado de (S)evilla. Sección Hermandades. Leg. 19. Autos sobre la utilización del título de Archicofradía. Año 1733, f. 49r.

28. A.H.S.P.S. Sección Sacramental. Leg. 46. Mayordomia 1650-1700. Cuentas de 1693.

29. A.H.S.P.S. Sección Sacramental. Leg. 59. Solicitudes de ingreso hasta 1695.

30. A.H.S.P.S. Sección Sacramental. Leg. 48. Mayordomia 1716-1735. Cuentas de 1734. "20 reales del entierro de Diego Gallegos". 
Volviendo a las ocho jarritas, éstas miden $13 \mathrm{cms}$. de alto; presentan una peana circular, cuerpo piriforme invertido y dos asas laterales en forma de volutas caladas. La decoración se realiza a base de flores y tallos, cuyos perfiles se matizan con punteado. En origen, estas jarras se enriquecieron con ramilletes florales de seda; ya en la primera mitad del siglo XIX, a cuatro de ellas se les acoplaron unos argénteos ramos de diez flores cada uno, procedentes de la peana de Nuestra Señora del Voto. Allí pueden distinguirse claveles, rosas y margaritas, coronándose los conos por una azucena (Lám. 3).

El 20 de febrero del referido año 1693, el maestro ensamblador y escultor Antonio de Quirós concierta por 600 reales la hechura de unas "cartelas y cartelones" para la "urna" o paso de la custodia, así como ocho columnas salomónicas en madera plateada, cuya misión era otorgar el apetecido efecto barroquizante ${ }^{31}$. Cuatro se colocaron en el primer cuerpo, mientras las restantes, de menores proporciones, se instalaron en el segundo. A nuestro juicio, dichas columnas fueron retiradas de su emplazamiento en la reforma neoclásica de 1821.

También deben pertenecer a la producción de Antonio de Quirós las figuras en terracota de los cuatro Evangelistas, destinados a los ángulos del banquillo del primer cuerpo de la custodia (Lám. 4). Aunque su estado de conservación es muy deficiente, con desgastes acentuados en su modelado, aún permanecen restos de su estofado en plata. Por cierto, sabemos que el 26 de junio de 1693 Mateo Parrilla concertó por 650 reales el plateado de todas las piezas de la custodia que no eran de dicho metal ${ }^{32}$. Estos Evangelistas -miden $29 \mathrm{cms}$. de alto- quedan imbuidos de un vigoroso dinamismo, especialmente patente en el vuelo de sus indumentarias, propio de la escultura sevillana de la segunda mitad del siglo XVII. Las efigies, representadas en actitud de escribir, se acompañan de sus respectivos símbolos parlantes; en su día contaron con diademas y plumas en plata, hoy perdidas. En los inventarios figuran como "modelos", lo cual quizás indique que la primera intención, nunca llevada a feliz término, sería convertirlos con posterioridad en esculturas de plata ${ }^{33}$.

Para finalizar con este apartado de reformas seiscentistas, anotaremos que en marzo de 1693 se ajustó con el platero Pedro Bernardo el cincelado de la nueva

31. A.H.S.P.S. Sección Sacramental. Leg. 46. Mayordomía 1650-1700. Cuentas de 1693. "Digo yo, Antonio de Quirós, que tengo ajustado con el Sr. D. Juan Francisco Freire, Diputado de la Cofradía del Santísimo Sacramento, cita en la Collegial de Nuestro Sr. San Salvador, el echar cartelas y cartelones a la urna y hazer ocho colunas salomónicas, y hazer todos los banquillos de ellas tallados. Y el aliño que toda la custodia nesecitare en seiscientos reales de vellón, y por quenta de ellos tengo resevidos trezientos y por lo que a cada uno toca lo firmamos en Sevilla, en 20 de febrero de 1693. Juan Francisco Freire y Antonio de Quirós (rúbricas)".

32. A.H.S.P.S. Sección Sacramental. Leg. 77. Capilla Sacramental y Custodia. "Títulos de la custodia de plata...".

33. A.H.S.P.S. Sección Sacramental. Leg. 1. Inventarios. "Libro de imbentarios...". Inventario 1-enero-1697, f. 21r-v. "Más quatro cartelas grandes y los ánjeles y ebanjelistas y ymagen de Nuestra Señora de la Conzepzión, que se hicieron para modelos"; "Yten quatro diademas de plata y quatro plumas de los ebanjelistas". 
peana de la custodia, al par que Diego Gallegos se encargaría de su repujado, hasta bruñirla, "sin obligazión de zinzel" ${ }^{34}$. Dicha peana, que se encontraba sumamente deteriorada, también ha sido restaurada en 1992 por Orfebrería Villarreal. La carnosa decoración vegetal que cubre sus cuatro caras proclama la filiación barroca de este espléndido escabel.

Durante el Setecientos, únicamente se registran los usuales "blanqueos" o limpiezas de la custodia, como las efectuadas en 1768 por José Carmona y en 1776 por José Alexandre, quien además consolidó las maderas de su estructura interna ${ }^{35}$.

Traspasados los umbrales del siglo XIX, la Sacramental del Salvador se planteó la necesidad de restaurar su custodia procesional, en vista de los numerosos daños y desperfectos que mostraba. En un Cabildo celebrado el 18 de julio de 1819 se informa que el coste de dicha intervención oscilaría entre los nueve y los diez mil reales, estando algunos devotos dispuestos a sufragarlos en parte con sus limosnas; además, había cierta cantidad de plata inutilizada, que podría aprovecharse para dicho fin ${ }^{36}$.

La deseada reparación se llevó a cabo en 1821 , de mano de uno de los plateros más prolíficos de la urbe hispalense. Nos referimos a Miguel Palomino y Sánchez, quien recibió al finalizar su labor un total de 5.675 reales. En primer lugar, enriqueció la peana con cuatro esquinas de plata, que sustituyeron a las que existían de hojalata; asimismo, añadió algunos fragmentos en su frente y en toda la escocia, así como doce sobrepuestos para cubrir las uniones. La reforma de mayor envergadura la acometió en el primer cuerpo de la custodia, quedando signado por elementos decorativos propios de la estética neoclásica practicada por Palomino ${ }^{37}$. Probablemente, se retiraron entonces las columnas salomónicas de madera plateada, opuestas a los criterios academicistas empleados en esta restauración, que dejó grabada su memoria en una inscripción ubicada en la base del aludido primer cuerpo: "ESTA CUSTO/DIA SE RRENO/BO EN EL A/ÑO DE/ 1821" 38.

Entre 1989 y 1992 se ha llevado a cabo la restauración integral de la custodia procesional en los talleres de Orfebrería Villarreal. Ha primado en todo momento un criterio de conservación, con un absoluto respeto hacia la obra original. El presupuesto de dicha actuación se elevó a 3.893 .046 pesetas ${ }^{39}$.

34. A.H.S.P.S. Sección Sacramental. Leg. 77. Capilla Sacramental y Custodia. "Títulos de la custodia de plata...".

35. A.H.S.P.S. Sección Sacramental. Leg. 50. Mayordomía 1761-1775. Cuentas de 1768, recibo $\mathrm{n}^{\circ}$ 27. Lo firmó José Carmona el 22 de julio de 1768 por 48 reales; Leg. 51. Mayordomía 1776-1790. Cuentas de 1776. Recibo de 300 reales, firmado el 12 de junio de 1776 por José Alexandre.

36. A.H.S.P.S. Sección Sacramental. Leg. 6. Libro $5^{\circ}$ de Acuerdos 1741-1826. Cabildo Ordinario 18-julio-1819, f. 373v.

37. A.H.S.P.S. Sección Sacramental. Leg. 77. Capilla Sacramental y Custodia. Expte. 77.2.

38. SANZ SERRANO, María Jesús: La Orfebrería Sevillana del Barroco. T. II. Op. cit., p. 309.

39. "Conservación, restauración e incremento del patrimonio material de la Hermandad (mayo 1988-mayo 1992)" en Boletín de la Archicofradía Sacramental de Pasión. Sevilla, mayo de 1992, p. 7. 


\section{B. ESTUDIO ESTILISTICO E ICONOGRAFICO.}

La única custodia de asiento que se conserva en la capital hispalense fechada en la primera mitad del siglo XVII es la de la Hermandad Sacramental del Salvador ${ }^{40}$. Su estética manierista la comparte con otros ejemplares andaluces seiscentistas, tales como las custodias de las iglesias de Nuestra Señora de la Asunción en Cabra (Pedro Sánchez de Luque, 1626), Santa María en Arcos de la Frontera (Antonio Carrillo, 1645) y Nuestra Señora de la Asunción en Santaella (Antonio de Alcántara, 1656) ${ }^{41}$.

A pesar de todas las reformas sufridas a lo largo de su centenaria historia, su aspecto actual conserva la pureza de líneas arquitectónicas, sobriedad de diseño y austeridad iconográfica que caracterizan la producción del Manierismo, en lo que a platería se refiere ${ }^{42}$. La custodia, cuyas medidas son $2,55 \mathrm{~ms}$. de alto sin la peana y 2,89 ms. con ella, es utilizada en nuestros días tanto en el Monumento eucarístico que la Hermandad de Pasión instala el Jueves Santo en la Capilla Sacramental del Salvador, tras haberse fusionado en 1918 ambas corporaciones ${ }^{43}$, como en la procesión que dicha Hermandad organiza el lunes infraoctava de Corpus.

La custodia descansa sobre la peana que labraran Pedro Bernardo y Diego Gallegos en 1693. Esta última presenta una planta cuadrada y achaflanada (mide $1,30 \mathrm{~ms}$. de lado X 0,34 m. de alto); parte de una moldura recta y lisa, seguida de otra convexa adornada con gallones y hojas alternadas, colocadas ambas por Villarreal, que labró la siguiente inscripción: "RESTAURADA POR ORFEBRERIA VILLARREAL AÑO 1992". Seguidamente se disponen una profunda escocia y un toro, recorridos verticalmente por ocho tiras sobrepuestas que cubren las uniones, asimismo repujadas por Villarreal. Toda la peana muestra una turgente y abigarrada decoración a base de flores y tallos vegetales de gran resalte. Las cuatro caras quedan centradas por cartelas con asuntos eucarísticos, a saber: el Ave Fénix, el Cordero apocalíptico sobre el Libro de los Siete Sellos, el León de Judá y el Arca de Noé. Este escabel remata en una nueva moldura lisa de Villarreal que sirve de enlace con la base de la custodia (Lám. 5).

El primer cuerpo de la custodia tiene planta cuadrada con salientes radiales rectangulares (mide $0,80 \mathrm{~m}$. de lado X 0,99 $\mathrm{m}$. de alto). Cada una de las caras del banco tiene una molduración tripartita, con sendas tarjas apaisadas en el centro,

40. SANZ SERRANO, María Jesús: La Orfebrería Sevillana del Barroco. T. I. Op. cit., p. 188.

41. HERNMARCK, Carl: Custodias procesionales en España. Madrid, 1987, pp. 222-227.

42. SANZ SERRANO, María Jesús: La Orfebrería Sevillana del Barroco. T. I. Op. cit., pp. 188-190 y T. П. Op. cit., pp. 307-309; HERNMARCK, Carl: Custodias procesionales en España. Op. cit., pp. 220-221; CARRERO RODRIGUEZ, Juan: Catálogo de la Exposición Los Tesoros. Sevilla, 1992, s.p. O.101.

43. RODA PEÑA, José: "La custodia procesional de la Archicofradía Sacramental de Pasión" en Diario $A B C$. Sevilla, 8 de junio de 1993, p. 80 . El domingo 6 de junio de 1993, la custodia volvió a procesionar, de manera extraordinaria, para conmemorar varias efemérides: el CDL Aniversario fundacional de la Archicofradía Sacramental del Salvador, el LXXV de su fusión con la Hermandad penitencial de Pasión, y la apertura del XIV Congreso Eucarístico Internacional de Sevilla. En esta ocasión figuró sobre el suntuoso paso de plata del Nazareno de Pasión, labrado por Cayetano González. Dicha salida procesional se ha institucionalizado desde 1995. 
conteniendo la leyenda ya transcrita sobre la propiedad y fecha de terminación de la custodia, flanqueadas por rectángulos con decoración protobarroca a base de cintas planas, tallos y cabezas de querubes. Los referidos salientes angulares se oman en sus frentes con los símbolos del Tetramorfos: águila y ángel en la delantera, toro y león en la trasera; sobre dichos salientes se colocarían las ya analizadas esculturas de los Evangelistas, aunque a veces también se han situado allí cuatro de las jarritas con los ramos de plata, obras de Diego Gallegos en 1693.

Este cuerpo cuenta con 16 columnas de orden jónico, cuatro en cada esquina, que se disponen pareadas en ángulo recto. Sus dos tercios superiores se hallan estriados, mientras que el inferior se adorna con pámpanos, espigas y grutescos. Dichas columnas soportan cuatro arcos de medio punto y otros tantos vanos ovales. En el entablamento superior se aprecian otros cuatro salientes, donde encajarían las columnas salomónicas que se retiraron en la restauración de 1821. De hecho, todo el primer cuerpo muestra las huellas de esta labor, emprendida como sabemos por Miguel Palomino; el friso de hojas de laurel y la técnica de ejecución de las columnas nos remiten a la poética neoclásica practicada por dicho autor. La bóveda interior de este cuerpo, en el que se cobija el ostensorio, es rebajada y está dividida por ocho plementos, cada uno de los cuales se decora con cartones recortados formando "ces", espigas, racimos de uvas, veneras, pájaros y el pelícano eucarístico (Lám. 6).

El segundo cuerpo se conserva prácticamente en su prístino estado, por lo que respecta a sus elementos estructurales y decorativos (mide 0,615 m. de lado X 1,56 ms. de alto, incluyendo la cúpula y remate). Repite la misma planta del cuerpo inferior, con friso corrido en el banco, ornado con cintas y tallos vegetales, flores, pámpanos, aves, etc.; en el centro de las cuatro caras se inscriben cartelas, rodeadas por un contario y flanqueadas por dos pájaros. En alzado sustituirá las 16 columnas jónicas por otras tantas corintias, con sus fustes completamente cubiertos de cintas planas, tormapuntas en "ces" y "eses", óvalos, gallones, cabezas de querubines, tarjas y ramos de uvas y frutales. En las enjutas exteriores de los arcos de medio punto hay relieves con ángeles mancebos que tañen instrumentos musicales: lira, órganos portátiles, laúd, arpa, sacabuche, guitarra y pífano. Este cuerpo, que aloja en su interior la escultura barroca del Cristo atado a la columna, se cubre con cúpula de media naranja, rebajada al interior. Dicho intradós también se divide en ocho plementos, que convergen en un florón central; los cuatro de superficie menor llevan ovalos con la siguiente inscripción:

1.- "ESTA/ CUSTODIA/ SE RESTAURO/ EN SU/ TOTALIDAD"

2.- "EN EL/ TALLER DE/ ORFEBRERIA/ VILLARREAL/ EL AÑO/ 1992" 


\section{3.- "SIENDO/ HERMANO/MAYOR/ D. FRANCISCO/ NAVARRO/SANCHEZ/} DEL CAMPO"

4.- "Y/MAYORDOMO/SACRAMENTAL/D. CARLOS/ MURUBE/SALVATIERRA" ${ }^{44}$.

Los plementos mayores carecen de ornamentación figurada, presentando el consabido repertorio de cintas y tallos vegetales de cierto relieve. El volado entablamento también presenta los salientes esquineros que indican la posición ocupada antaño por las cuatro columnas salomónicas superiores. Por encima corre lo que pudiéramos identificar con el tambor de la cúpula, con otros nuevos salientes en los que se han instalado los cuatro angelillos fundidos en plata, datados entre $1670 \mathrm{y}$ 1672 , que aunque en origen pudieron ser turiferarios, hoy han perdido sus incensarios (miden $11 \mathrm{cms}$. de alto sin peana). El casquete semiesférico de la cúpula queda dividido en ocho segmentos por nervios que reposan sobre plintos. En su decoración aparecen gallones y puntas de diamantes, "ces" afrontadas, tarjas con óvalos, cartones recortados, etc.

La custodia se corona con un templete, a manera de edículo con vanos adintelados, en cuyo interior se aloja una campana. Sobre la pequeña cúpula peraltada del mismo apea la escultura cimera de la $\mathrm{Fe}$ (mide $30 \mathrm{cms}$. de alto sin peana). Su composición abierta, dinámica actitud e indumentaria de violento drapeado, confirman su datación en 1691. Se representa según la iconografía tradicional: coronada, ojos vendados, alzando el cáliz-ostensorio en la mano derecha y portando una banderola en la siniestra, cuya vara es una cruz arbórea (Lám. 7).

44. Se produjo una pequeña errata en la inscripción, ya que el segundo apellido del entonces Mayordomo Sacramental era "Salvatella" y no "Salvatierra". 


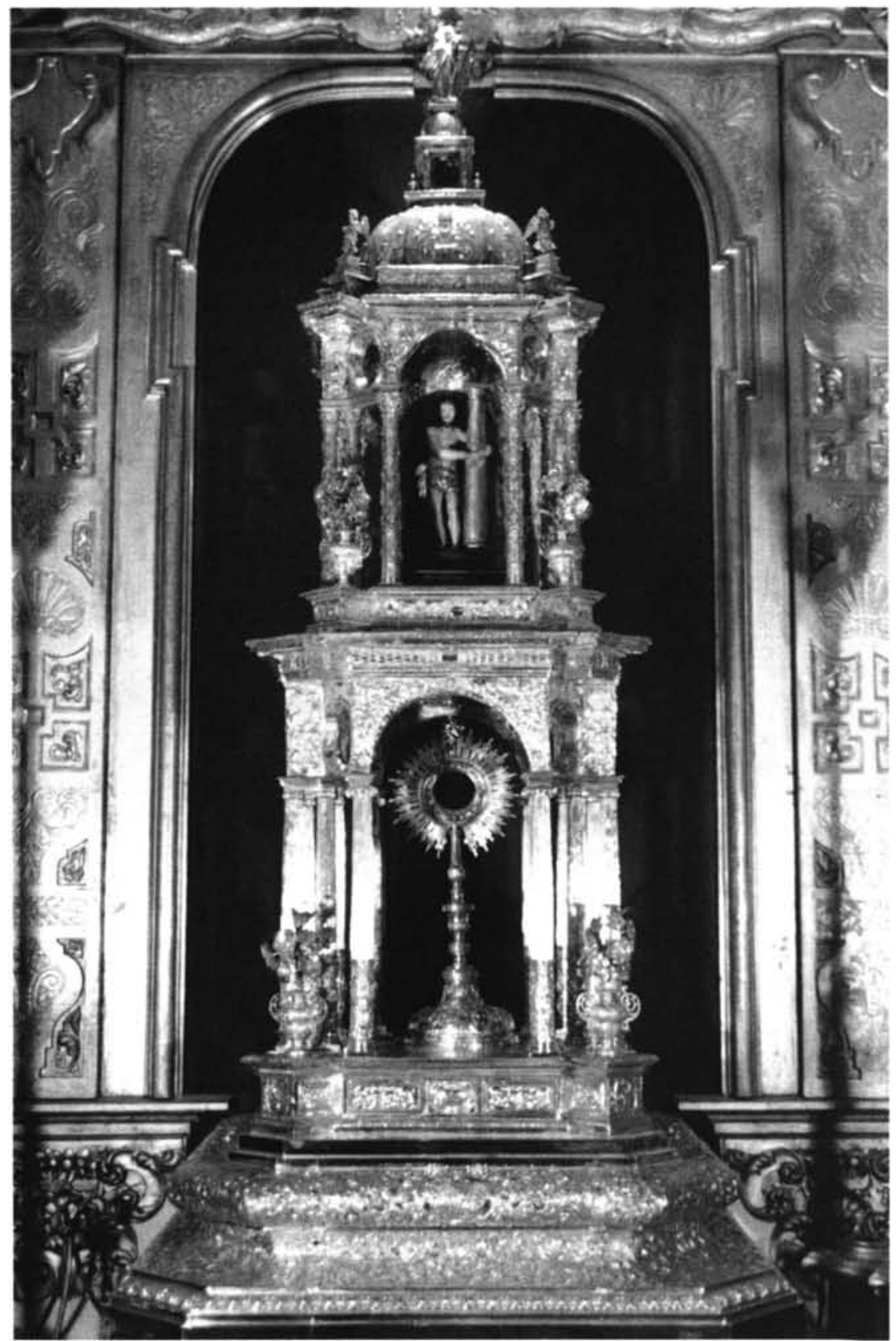

Lám. 1

Miguel Sánchez. Custodia procesional del Salvador. 1612-1621. 


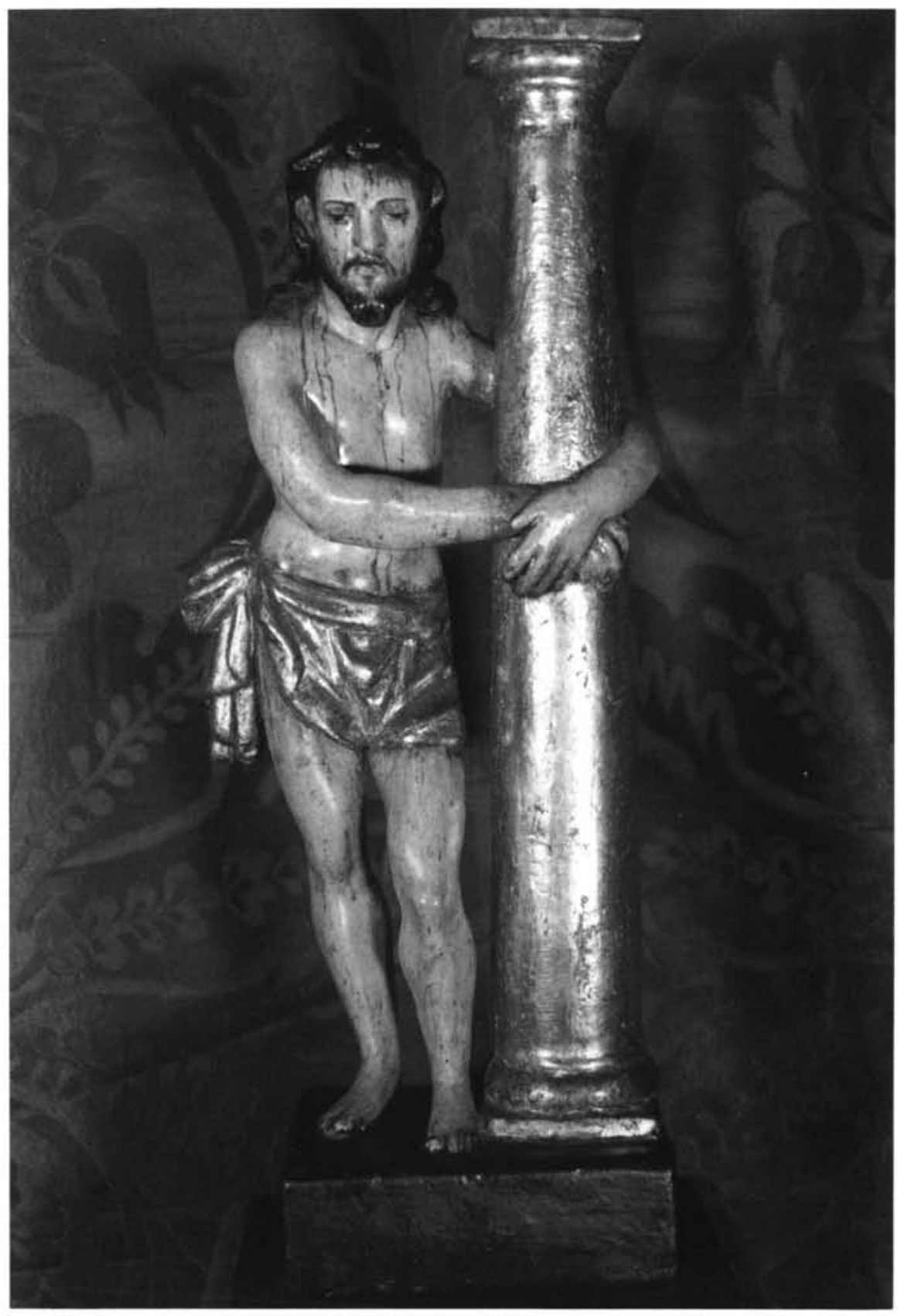

Lám. 2

Obra anónima sevillana. Cristo atado a la columna. Hacia 1650-1675. 


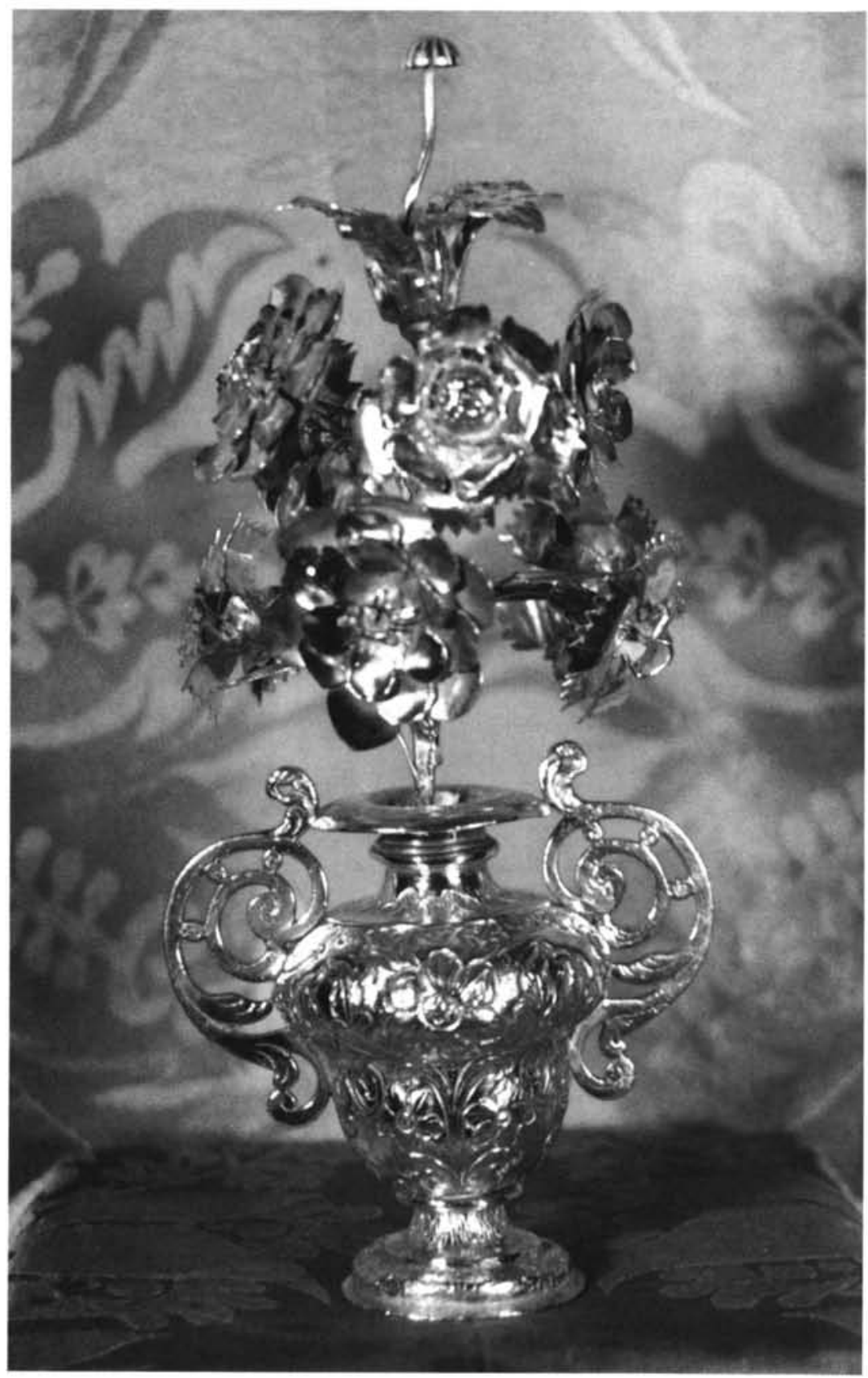

Lám. 3

Diego Gallegos. Jarra. 1693. 


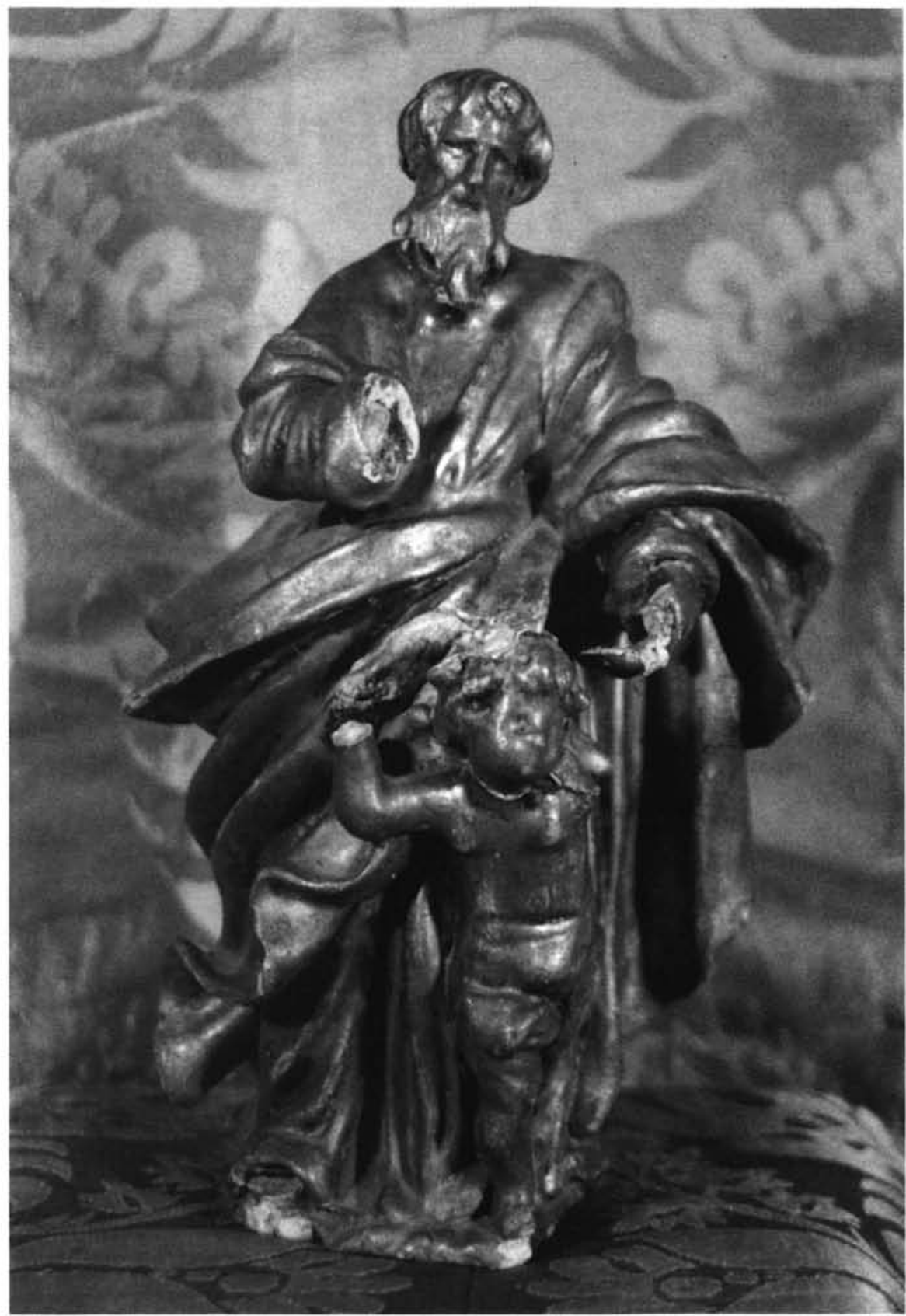

Lám. 4

Atribuido a Antonio de Quirós. San Mateo. 1693. 


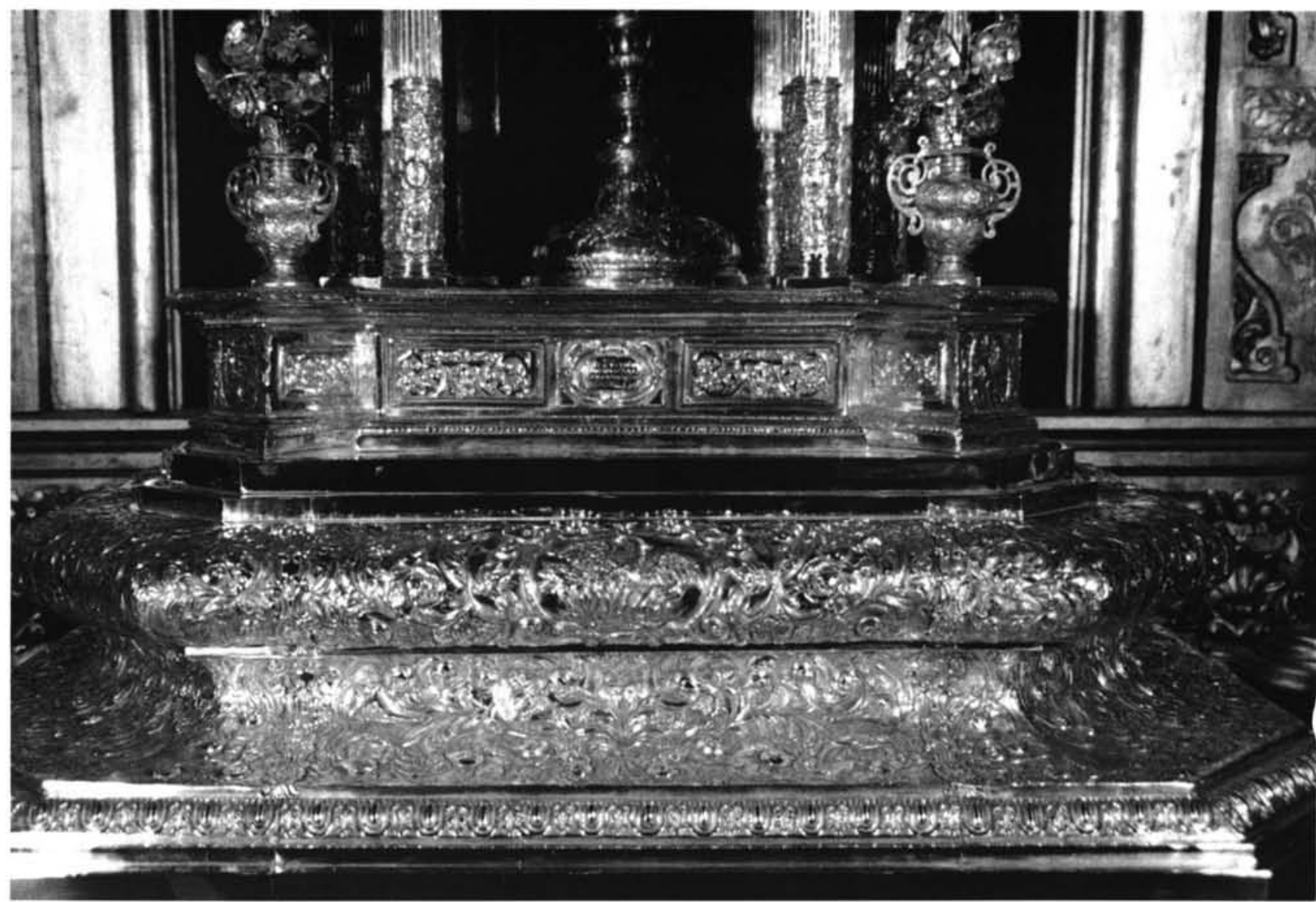




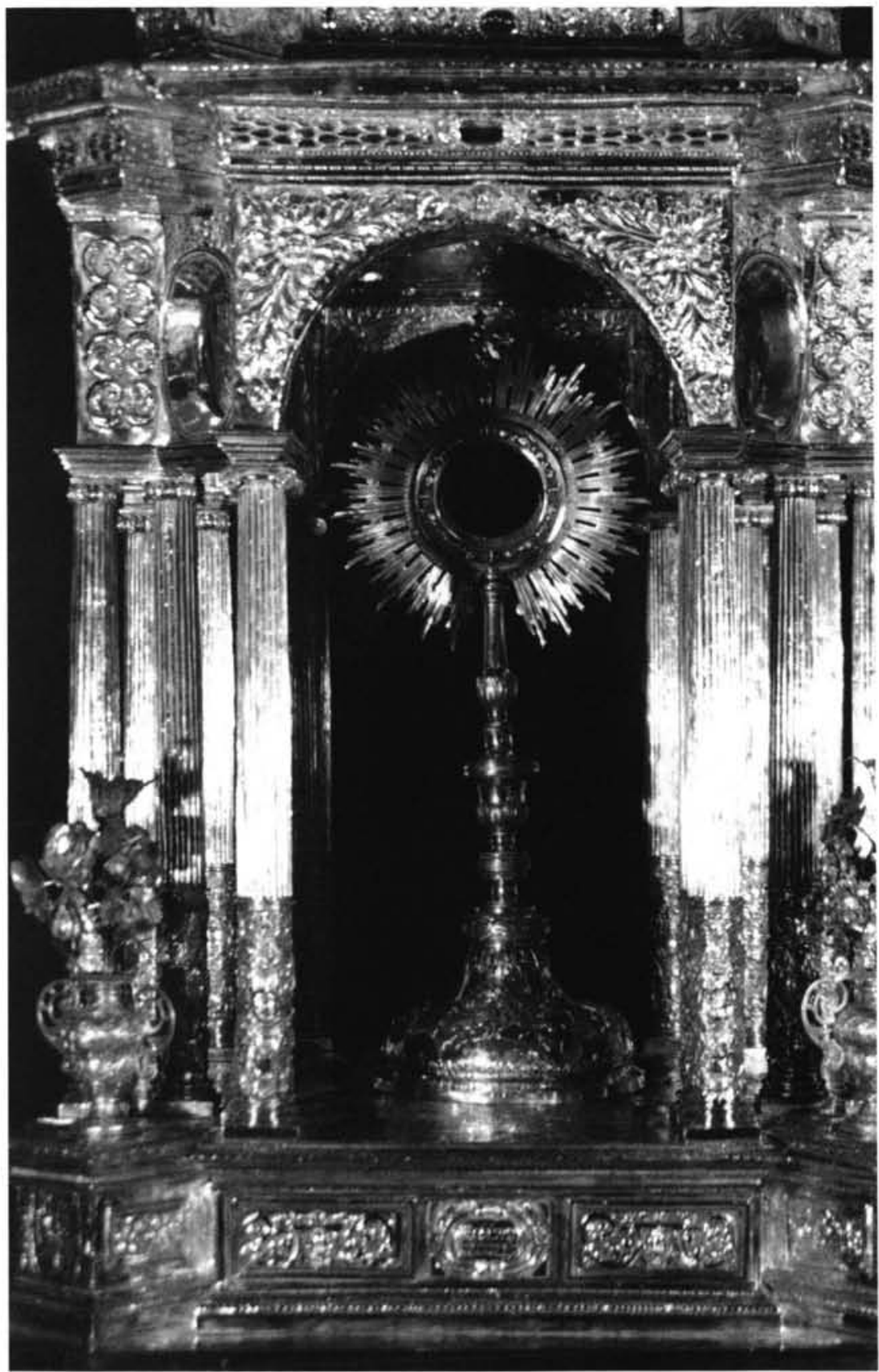

Lám. 6

Primer cuerpo de la custodia procesional del Salvador. 


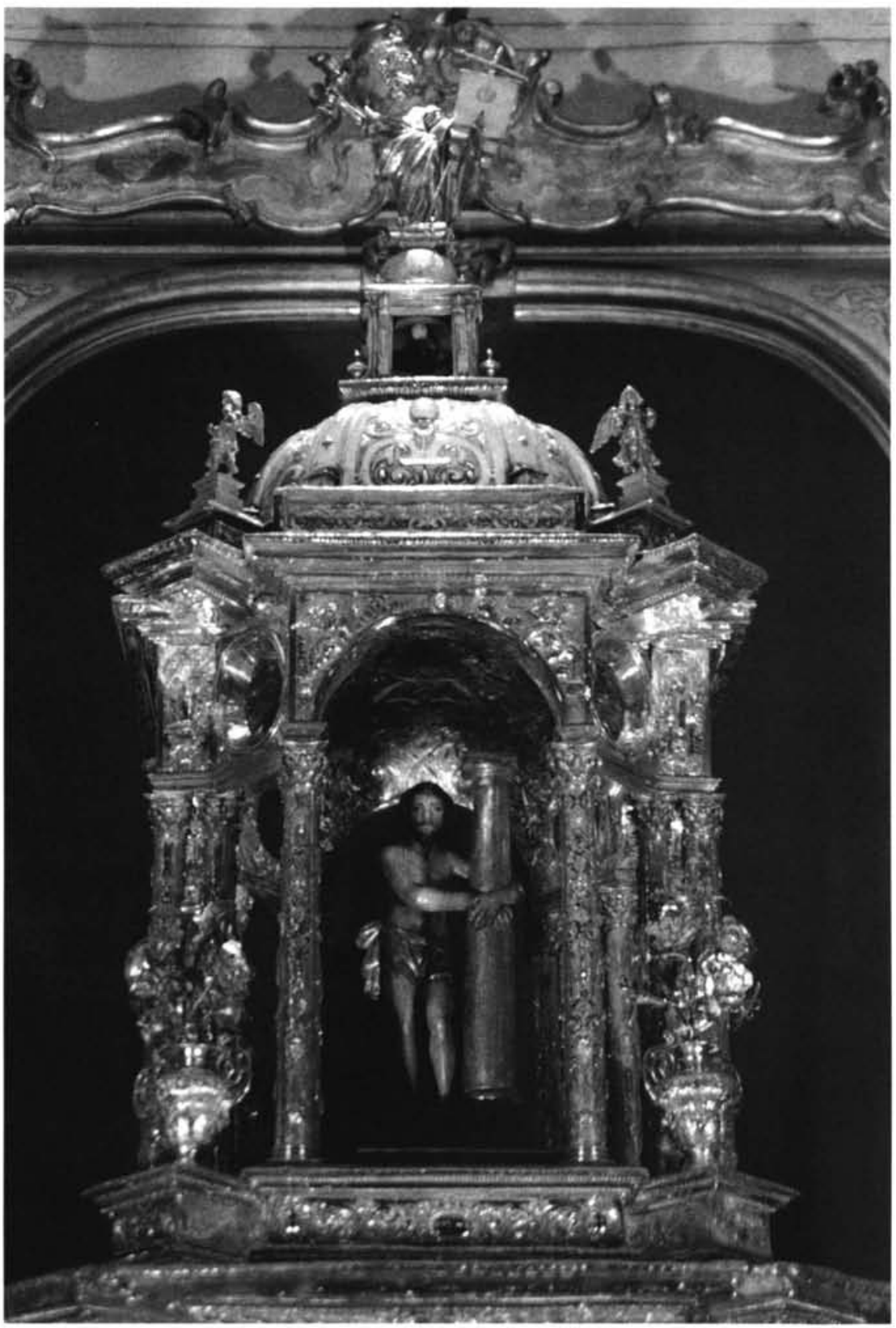

Lám. 7

Segundo cuerpo y remate de la custodia procesional del Salvador. 